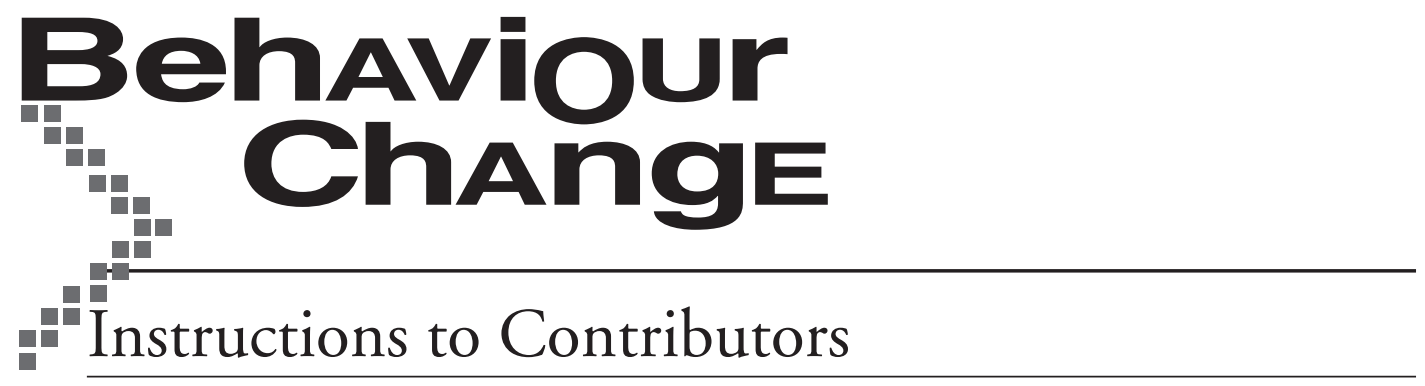

1. To be reviewed for possible publication in this journal all authors must follow the instructions below and submit their manuscript to:

https://www.australianacademicpress.com.au/cup_jsm/ All articles are refereed. Papers submitted to the journal must not previously have been published nor submitted for publication to any other journal.

2. Papers should be submitted via e-mail in Word or RTF format. Authors who wish to submit their paper in hard copy format may do so by arrangement with the editor.

3. Contributions should follow the format and style described in the Publication Manual of the American Psychological Association (5th ed.). Spelling and punctuation should conform to The Macquarie Dictionary (4th ed.). For matters of style not covered in these two publications the Style Manual for Authors, Editors and Printers (6th ed.) should be consulted.

4. Documents should be double-spaced with minimum margins of $20 \mathrm{~mm}$ on the left and $35 \mathrm{~mm}$ on the right. Uncommon abbreviations and acronyms should be explained. Do not use underlining except to indicate italics. Full stops should not be used in abbreviations or acronyms (e.g., NSW).

5. Use single quotation marks to introduce a word or phrase used as an ironic comment, as slang, or which has been coined. Use quotation marks the first time the word or phrase is used; do not use them again. Do not use quotation marks to introduce a technical or key term. Instead, italicise the term.

6. Front page: under the title of the article only the names and affiliations of the authors appear. Qualifications, present appointments, and postal and e-mail addresses should be given in a separate section on the front page labelled 'Address for correspondence'. A word count and suggested running head of no more than 50 characters including spaces should also be provided.

7. Do not use any footnotes. Endnotes should be kept to a minimum and listed at the end of the text under the centred heading 'Endnotes'. Acknowledgments should be placed at the end of the article with a separate heading.

8. Tables should be at the end of the manuscript, not in the main text. Their approximate positions in the text should be indicated by the words, 'Insert Table X here'. Horizontal and vertical lines should be used sparingly.

9. To ensure optimum quality, please follow these guidelines when submitting artwork via e-mail:

- Photographs, graphs and figures should be prepared to the correct size (max. width up to $120 \mathrm{~mm}$ ) and each one supplied as an individual file, separate to the manuscript Word file. Include placement instructions in the Word document, such as 'Insert Figure 1 here'.
- Figures created in Microsoft Word or Powerpoint need to be saved as PDFs.

- Figures created in a drawing program such as Adobe Illustrator, CorelDRAW, Freehand, Microsoft Publisher or similar should be saved as EPS (encapsulated postscript) files.

- Figures created in Photoshop or with other photographic software should be saved as line art (artwork that has only text and lines, no shades of grey or blocks of colour) with a minimum resolution of 600 dpi and in TIF format. Minimum resolution for scanned graphics is 300 dpi for halftone work (e.g., photographs) and $600 \mathrm{dpi}$ for line art, and these should also be in TIF format.

- Manuscripts that contain equations created with LaTeX or similar specialist software need to be supplied as a PDF file as well as a Microsoft Word document.

- Prior to sending artwork, the separate files of figures, graphs, illustrations, etc. should be printed by the author to test that the fonts have been embedded correctly and there is no distortion in the artwork (e.g., lines and fonts reproduce cleanly with no jagged lines or fuzzy edges), as any such faults cannot be corrected by the publisher.

- Preferred media for delivery: e-mail as attachments, Macintosh or PC floppy disk, Macintosh or PC Zip disk, CD-ROM. If your artwork does not meet these guidelines, it may be returned to you.

10. References and citations should follow the format and style described in the Publication Manual of the American Psychological Association (5th ed.). Examples of citations are:

The theory was first propounded in 1970 (Larsen, 1971).

Larsen (1971) was the first to propound the theory.

Examples of references are:

Fisse, B. (1989). The proceeds of crime act: The rise of money laundering, offences and the fall of principle. Criminal Law Journal, 13, 5-23.

Zelinski, E.M., \& Gilewski, M.J. (1988). Memory for prose and aging: A meta-analysis. In M.L. Howe \& C.J. Brainerd (Eds.), Cognitive development in adulthood (pp. 133-158). New York: SpringerVerlag.

11. Authors are expected to check the accuracy of all references and citations in the manuscript before submission. 


\section{VOLUME 29 ISSUE 1}

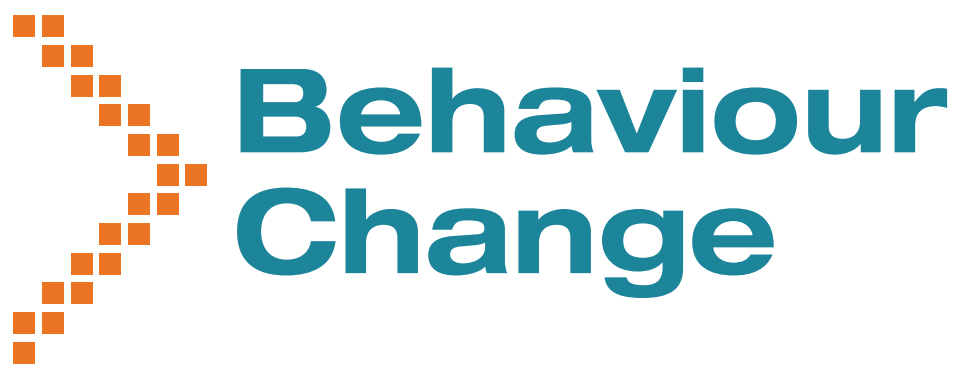

\section{Contents}

- The FRIENDS for Life Program for Mexican Girls Living in an Orphanage: A Pilot Study

Julia Gallegos, Alejandra Rodríguez, Graciela Gómez, Marisol Rabelo, and Mónica Fernanda Gutiérrez

- Online Exposure Treatment for Spider Fear: The Effects of Moving Versus Static Images on Treatment Adherence, Fear Elicitation and Habituation

Allison J. Matthews, Joel D. Scanlan, and Ken C. Kirkby

- The Relationship Between Experiential Avoidance and Impulsiveness in a Nonclinical Sample

Christopher R. Berghoff, Andrew M. Pomerantz, Jonathan C. Pettibone, Daniel J. Segrist, and David R. Bedwell

- Treatment Acceptability and Psychosocial Outcomes of a Randomised Controlled Trial of a Cognitive Behavioural Lifestyle Intervention for Overweight and Obese Adolescents Leah Brennan, Ray Wilks, Jeff Walkley, Steve F. Fraser, and Kate Greenway 